\title{
A Dominant Role of Acid pH in Inflammatory Excitation and Sensitization of Nociceptors in Rat Skin, in vitro
}

\author{
Kay H. Steen, ${ }^{2}$ Astrid E. Steen, ${ }^{1}$ and Peter W. Reeh ${ }^{1}$ \\ 'Institut für Physiologie I, Universität Erlangen-Nürnberg, D-91054 Erlangen, Germany and 'Universitäts-Hautklinik \\ und Poliklinik der Universität Bonn, D-53105 Bonn, Germany
}

\begin{abstract}
A major role of local acidosis in long lasting excitation and sensitization of cutaneous nociceptors has recently been demonstrated. In inflamed tissue, acid pH meets with a mixture of inflammatory mediators which, by themselves, stimulate nociceptors though being subject to profound tachyphylaxis. We have mimicked this condition in a rat skin-saphenous nerve preparation in vitro which allows direct application of chemicals to the isolated receptive fields at the corium side. Stimulant solutions used were $\mathrm{CO}_{2}$-saturated "synthetic interstitial fluid" $\left(\mathrm{CO}_{2}-\mathrm{SIF}, \mathrm{pH} 6.1\right)$, an "inflammatory soup" (IS) in submaximal concentration containing bradykinin, 5-HT, histamine, prostaglandin $\mathrm{E}_{2}$ (all $10^{-6} \mathrm{M}$ in SIF at $38.5^{\circ} \mathrm{C}$ and $\mathrm{pH} 7.0$ ), and a combination made of $\mathrm{CO}_{2}$-saturated IS $\left(\mathrm{CO}_{2}-\mathrm{IS}, \mathrm{pH} 6.1\right)$. Identified mechanoheat sensitive ("polymodal") C-fiber terminals $(n=36)$ were treated with these solutions for $5 \mathrm{~min}$ at $10 \mathrm{~min}$ intervals or for $\mathbf{3 0} \mathrm{min}$ of sustained stimulation: $\mathbf{2 0}$ units responded to $\mathrm{CO}_{2}$-SIF, 12 to IS, whereas 27 units $(75 \%)$ were excited by $\mathrm{CO}_{2}-1 \mathrm{~S}$. Thus, 6 out of 15 units insensitive to either of the two basic solutions were stimulated by their combination. This enhanced effect of $\mathrm{CO}_{2}$-IS was also expressed in shorter latencies (than with $\mathrm{CO}_{2}$-SIF) and in a significantly larger mean response magnitude of the fiber population: 152 spikes with the combination versus 45 spikes evoked by IS and 93 spikes by $\mathrm{CO}_{2}$-SIF $(n=25 ; p$ $<0.002$ and $<0.02$, respectively, Wilcoxon test). The synergistic interaction between $\mathrm{CO}_{2}$ and IS also showed up during sustained nociceptor stimulation (30 $\mathrm{min}$ ) by either $\mathrm{CO}_{2}$-SIF $(n=7)$ or IS $(n=1)$ when, during the middle 10 min, $\mathrm{CO}_{2}-$ IS was applied which significantly increased the discharge.
\end{abstract}

There is a strong, potentially algogenic, interaction between acid pH and inflammatory mediators in terms of prevalence and magnitude of nociceptor excitation. At equal and pathophysiologically relevant concentration, however, hydrogen ions play a dominant role.

[Key words: pain, protons, inflammatory mediators, cutaneous, sensory nerve endings, primary afferents]

Since von Frey (1896) concluded that "pain receptors" ought to be chemoreceptive in nature, scientists went in search of mediators of inflammatory pain. Although a general chemical me-

Received Sept. 16, 1994; revised Dec. 29, 1994; accepted Jan. 3, 1995.

This work was supported by DFG Grants Ste 593/1-2 and SFB 353 (A3). Thanks are due to K. Burian for his excellent graphical work.

Correspondence should be addressed to Dr. K. H. Steen, Universitäts-Hautklinik und Poliklinik der Universität Bonn. Sigmund Freud Strasse 25. D-53105 Bonn, Germany.

Copyright $\odot 1995$ Society for Neuroscience $0270-6474 / 95 / 153982-08 \$ 05.00 / 0$ diator of pain has not been identified, several endogenous agents have been found in inflammation and were shown to excite nociceptive nerve endings (Fjällbrand and lggo, 1961). With in vitro techniques used for the study of afferent nerve endings in mammalian skin, it was shown that the hormonal mediators of inflammation could not excite all nociceptors and were subject to profound tachyphylaxis (Lang et al., 1990). Only a combination of these mediators (bradykinin, 5-HT, histamine, and prostaglandin) in very high concentration $\left(10^{-5} \mathrm{M}\right)$ was able to excite cutaneous nociceptors in vitro for a sustained period of $30 \mathrm{~min}$ (Reischl et al., unpublished observations). Considerably lower concentrations of bradykinin $\left(2 \times 10^{-8} \mathrm{M}\right)$ and prostaglandin $\left(10^{-7} \mathrm{M}\right)$, at least, have been found in inflamed tissue (see Handwerker and Reeh, 1991).

High hydrogen ion concentrations have been found in inflamed tissue (down to $\mathrm{pH} 5.4$ ), in fracture-related hematomas (down to $\mathrm{pH} 4.7$ ), in cardiac ischemia (down to $\mathrm{pH} 5.7$ ) and in and around malignant tumors (Häbler, 1929; Revici et al., 1949; Peer, 1955; Jacobus et al., 1977). Therefore, local acidosis has been suggested to provide the causal link between these diseases and their related pain (von Gaza and Brandi, 1926; Keele and Armstrong, 1964; Lindahl, 1974). Indeed, electrophysiological experiments in a rat skin nerve preparation in vitro showed that pathophysiologically relevant $\mathrm{pH}$ values $(6.1-6.9$ threshold) produced a selective nonadapting excitation of nociceptors and a significant sensitization to mechanical stimulation. Thus, it has been proposed that local acidosis plays a major role in cutaneous pain and hyperalgesia (Steen et al., 1992). However, previous psychophysiological work on the duration of $\mathrm{pH}$-induced pain remained inconclusive since, methodically, the buffering capacity and counterregulations of the intact tissue were not taken into account. Only recently it was demonstrated that continuous intracutaneous infiltration of low $\mathrm{pH}$ buffer ( $\mathrm{pH}$ 5.2) into human skin is able to induce sustained localized pain without adaptation (Steen and Reeh, 1993).

In inflamed or injured tissue several potent mediators meet in the interstitial fluid and form an inflammatory exudate. Bradykinin (BK) results from enzymatic actions on a plasma protein precursor, serotonin $(5-\mathrm{HT})$ is released from mast cells (in the rat) and from activated thrombocytes and potentiates the excitatory action of BK on nociceptors (Fock and Mense, 1976; Lang et al., 1990). Histamine (HIS) is set free from mast cells and from invading basophilic leukocytes; its weak action on nociceptors is amplified by preceding BK (Koppert et al., 1993). The mediators cooperate in triggering synthesis of eicosanoids which, in turn, enhance the inflammatory symptoms vasodilatation and plasma extravasation and attract inflammatory blood 
cells. These leukocytes actively pump lactic acid into the exudate lowering the $\mathrm{pH}$ (McCarty et al., 1966) which, by itself, is a potent nociceptive stimulus. The open question in this respect is whether the different mediators would combine their effects in exciting nociceptors. Such synergism had previously been demonstrated for some of the above tissue hormones (Lang et al., 1990; Kessler et al., 1992) forming an experimental "inflammatory soup" which, however, did not contain high proton concentration (just $\mathrm{pH} 7.0$ ). It was the aim of the present study to evaluate possible interactions between inflammatory mediators and low $\mathrm{pH}$. The experiments were designed to quantify the role of equal and of pathophysiologically relevant concentrations of the compounds.

Some of the results have previously been communicated as abstracts (Reeh et al., 1991; Steen et al., 1991).

\section{Materials and Methods}

Preparation. A rat skin nerve preparation in vitro was used which provided control over the chemical environment of nociceptive nerve terminals and allowed conventional single fiber recordings from identified primary afferents. This has previously been described in detail (Reeh, 1986). The preparation was taken from 28 male Wistar rats (350-550 gm body weight) anesthetized with sodium thiopental $(120 \mathrm{mg} / \mathrm{kg}$, i.p.) and killed by an intracardial injection of $2 \mathrm{ml}$ of lidocaine after the dissection. The saphenous nerve, together with the complete skin flap of the dorsal hind paw and of the lower third of the leg, was subcutaneously excised and superfused in an organ bath with a "synthetic interstitial fluid" (SIF; Bretag, 1969), a solution consisting of $107 \mathrm{~mm}$ $\mathrm{NaCl}, 26.2 \mathrm{~mm} \mathrm{NaHCO}, 9.64 \mathrm{~mm}$ sodium gluconate, $5.5 \mathrm{~mm}$ glucose, $7.6 \mathrm{~mm}$ sucrose, $3.48 \mathrm{mM} \mathrm{KCl}, 1.67 \mathrm{~mm} \mathrm{NaH} \mathrm{PO}_{4}, 1.53 \mathrm{~mm} \mathrm{CaCl}_{2}$ $0.69 \mathrm{~mm} \mathrm{MgSO}$ at $32^{\circ} \mathrm{C}\left( \pm 0.5^{\circ} \mathrm{C}\right)$, continuously bubbled with carbogen $\left(95 \% \mathrm{O}_{2}\right.$ and $\left.5 \% \mathrm{CO}_{2}\right)$, which leads to $\mathrm{pH} 7.4$. While one preparation was stored at $4{ }^{\circ} \mathrm{C}$ in the electrolyte solution to be used later in the day, the other skin flap was mounted, epidermal side down, in the tissue chamber and which was perfused with oxygenated SIF $(14 \mathrm{ml}$ min). The saphenous nerve was drawn through a hole into a second chamber where small filaments were split and further subdivided unti single unit activity could be recorded monopolarly via gold wire electrodes. For that, the aqueous solution was overlaid by a layer of paraffin oil and a reference electrode located in the organ bath nearby.

Identification and characterization of $C$-fiber activity. The innervation of the skin was tested with a blunt glass rod mechanically searching for the receptive field of a nerve fiber. The nerve endings localized were electrically stimulated with Teflon-insulated steel microelectrodes to measure conduction velocity and to establish the identity of mechanically and electrically evoked action potentials with the "collision technique" (Iggo, 1958). The thresholds to punctuate mechanical stimulation were tested with a set of von Frey hairs made from nylon filaments with uniform tips $(0.9 \mathrm{~mm}$ diameter) and calibrated in the form of a geometric series $\left(x_{i}=x_{i-1}, \sqrt{2}\right)$ ranging from 1 to $362 \mathrm{mN}$.

In order to test the heat sensitivity, a halogen bulb was posted below the translucent bottom of the skin chamber to apply radiant heat stimuli onto the epidermal surface of the receptive field. On the corium side, the temperature was feedback-controlled with a thermocouple and, for the purpose of stimulation, was raised in form of a ramp from $32^{\circ} \mathrm{C}$ to $46^{\circ} \mathrm{C}$ over a period of $20 \mathrm{sec}$ which corresponds to a rise from $32^{\circ} \mathrm{C}$ to $52^{\circ} \mathrm{C}$ at the epidermal surface (Reeh, 1986). To prevent measuring errors due to thermal convection, a metal ring was placed over the receptive field and the fluid in the ring was sucked off. For cold stimulation, the same ring was filled with cold SIF $\left(4^{\circ} \mathrm{C}\right)$, and the time course of the temperature was monitored.

Chemical stimulation and experimental protocol. To restrict the spread of agents during chemical stimulation, the receptive fields were isolated using metal rings with inner diameters of $6.6-9.6 \mathrm{~mm}$ (height $7.7 \mathrm{~mm}$ ) which comprised volumes of $0.3-0.6 \mathrm{ml}$ and were perfused at $38.5^{\circ} \mathrm{C}$ with a turbulent flow of $2.25 \mathrm{ml} / \mathrm{min}$. When the perfusion was switched from normal SIF to stimulating solutions or vice versa, the ring chamber was emptied just prior to the arrival of the new fluid in order to provide an instantaneous change of the solutions. The chemical stimulations followed experimental protocols which are displayed along the abscissae of the figures and had proven suitable in previous works (Kessler et al., 1992; Steen et al., 1992). For short-term stimulation, a
5 min period of superfusion with acid $\mathrm{pH}\left(\mathrm{CO}_{2}\right.$-saturated SIF; $\left.\mathrm{pH} 6.1\right)$ was followed by a washout interval of $10 \mathrm{~min}$, in which period the afterdischarge had faded away in all cases. A 5 min period of stimulation joined using a broad mixture of inflammatory mediators ("inflammatory soup," IS, containing bradykinin, 5-HT, histamine, and prostaglandin $\mathrm{E}_{2}$, all $10^{-6} \mathrm{M}$ ) and this was followed by $10 \mathrm{~min}$ washout. Finally, a combination of low $\mathrm{pH}$ and the "inflammatory soup" $\left(\mathrm{CO}_{2}\right.$ IS; pH 6.1), was applied during $5 \mathrm{~min}$ and was followed by a final washout period (see Fig. 1 for examples). In a few cases the order of stimulation was changed by starting with IS, followed by $\mathrm{CO}_{2}-\mathrm{SIF}$, and finally $\mathrm{CO}_{2}$-IS was applied. For long-term stimulation during a period of $30 \mathrm{~min}, \mathrm{CO}_{2}$-saturated SIF ( $\mathrm{pH} \mathrm{6.1)} \mathrm{was} \mathrm{applied} \mathrm{and} \mathrm{inflammatory}$ mediators were added $\left(\mathrm{CO}_{2}-\mathrm{IS}\right)$ during the middle $10 \mathrm{~min}$ period. In a reverse long-term protocol, a $30 \mathrm{~min}$ stimulus of IS was interrupted by $\mathrm{CO}_{2}$-IS during the middle $10 \mathrm{~min}$ period (see Fig. 4).

The IS was made up of prostaglandin $\mathrm{E}_{2}$ (SERVA, freshly prepared from an oxygen-free stock solution containing $0.3 \%$ ethanol), histamine triacetate (Sigma), 5-HT hydrochloride (Sigma), and bradykinin triacetate (Sigma) which were dissolved in SIF at concentrations of $10^{-6} \mathrm{M}$; the $\mathrm{pH}$ was titrated to 7.0 with $\mathrm{HCl}$, and the potassium concentration was raised to $7 \mathrm{mM} \mathrm{K}^{+}$by adding $\mathrm{KCl}$ (for consistency with Kessler et al., 1992). This solution was applied at $38.5^{\circ} \mathrm{C}$. For acidification, SIF or IS were continuously gassed with pure $\mathrm{CO}_{2}$ which led to a constant $\mathrm{pH}$ of 6.1 (Steen et al., 1992).

In the previous work it has been shown, by using control stimuli (oxygenated phosphate puffer, $\mathrm{pH} 6.1$ ), that low, probably intracellular $\mathrm{pH}$ is the specific stimulus for the excitation of nociceptors; the acid phosphate buffer excited an identical fiber-population and induced an equal magnitude of nociceptive response as the $\mathrm{CO}_{2}$-saturated solutions of the same $\mathrm{pH}$. A dose-response curve has been achieved by varying the $\mathrm{pH}$ of the phosphate buffered solution. The acidification by means of $\mathrm{CO}_{2}$ led to a comparatively reduced latency of the response by easier penetration through the neuronal membrane, and the effect was effectively antagonized by using the carboanhydrase blocker acetazolamide (Steen et al., 1992).

Criteria of responsiveness of fibers. All units had to be silent in order to be included in this study. Therefore, an occasional spontaneously active fibcr, occurring mostly as a result of heat stimulation, was not further investigated. A unit was regarded as responsive if the evoked discharge of the fiber could be washed out after chemical stimulation, and if the response was reproducible using the same agent (IS or $\mathrm{CO}_{2-}$ $\mathrm{SIF}$ ) or the combination $\left(\mathrm{CO}_{2}\right.$-IS). In this study, we did not follow any arbitrary response criterion of a minimum discharge rate exceeded, since $10^{-6} \mathrm{M}$ IS concentration had to be regarded as a threshold concentration for many units. Hence, in some cases the discharge rate was below the threshold to induce a pain sensation (1 spike/sec) in microneurography studies in human subjects (Handwerker et al., 1991). The magnitude of the responses to the different stimulations was assessed as the total number of spikes counted during a sampling period of 15 min after stimulus onset, that is, $5 \mathrm{~min}$ of stimulation and subsequent 10 min of the washout period. Therefore, "spikes/15 min" (in Figs. 2, 3) does not mean an average discharge rate but rather the total number of spikes per response; the actual duration of the response was usually much shorter. For the long-term stimulation, which required a period of $30 \mathrm{~min}$ and a subsequent washout phase of $10 \mathrm{~min}$, we counted the total number of spikes during these $40 \mathrm{~min}$.

Data analysis. The single nerve fiber activity was recorded, amplified, and passed through a window discriminator, and the normed pulses were recorded on line on an AT 386 type computer using the CED 1401 interface and SPIKE 2 software (CED, Cambridge, England). The SIGMAPLOT software package was used for supporting graphical presentation of the data (Jandel, Berkeley, CA). For statistical analyses, the Complete Statistical System (css, Statsoft, Tulsa, OK) was employed; to compare the different chemical responses within the fiber groups statistically the Wilcoxon matched pairs test was used, and its $p$ values are presented in the figures.

\section{Results}

\section{Population of afferent units}

The categorization of the units was based on established criteria of sensory properties and of conduction velocities found in nerves to rat hairy skin (Lynn and Carpenter, 1982; Fleischer et al., 1983). In this study, receptive fields of 47 primary afferents were superfused with a combination of inflammatory mediators, 
Table 1. Chemosensitivity of C-fibers

\begin{tabular}{llll} 
C-Fibers $(n=47)$ & MH & HTM & Others \\
\hline Fibers tested & 36 & 7 & 4 \\
Resp. to $\mathrm{CO}$ ( $1 \mathrm{pH} \mathrm{6.1)}$ & 20 & 2 & 0 \\
Resp. to IS $\left(10^{-6} \mathrm{M}\right)$ & 12 & 2 & 0 \\
Resp. to $\mathrm{CO}_{2}-\mathrm{IS}$ & 27 & 2 & 0
\end{tabular}

MH, Mechano-heat sensitive, "polymodal"; HTM, high-threshold mechanosensitive; "Others" were mechano-cold and low-threshold mechanosensitive C-fibers. $\mathrm{CO}_{2}$ "synthetic interstitial fluid" (SIF) gassed with pure $\mathrm{CO}_{2}$. IS "inflammatory soup": bradykinin, 5-HT, histamine, prostaglandin $\mathrm{E}_{2}$ in SIF Note that acidified "inflammatory soup" $\left(\mathrm{CO}_{2}-\mathrm{IS}\right)$ excited a number of polymodal nociceptors $(n=7)$ that had previously been insensitive to both chemical stimuli ( $\mathrm{CO}_{2}$ and IS).

"inflammatory soup" (IS), $\mathrm{CO}_{2}$-saturated "synthetic interstitial fluid" ( $\mathrm{CO}_{2}$-SIF, $\left.\mathrm{pH} 6.1\right)$, and a combination of both $\left(\mathrm{CO}_{2}-\mathrm{IS}\right.$, $\mathrm{pH}$ 6.1). The selection of single units was biased towards slow conducting nociceptive fibers. Therefore, the numbers of fibers shown in Table 1 are not representative for their relative frequency in rat skin. Since it has been shown before that rapidly adapting $A \delta$ and all types of $A \beta$ fibers are not excited or sensitized by acid $\mathrm{pH}$ (Steen et al., 1992) or inflammatory mediators (Kessler et al., 1992), they have not been included here. In pilot experiments, such fibers $(n=4)$ have proven to be also insensitive to the combination of substances $\left(\mathrm{CO}_{2}-\mathrm{IS}\right)$.

We identified 36 of the $47 \mathrm{C}$-fibers as mechano-heat sensitive (C-MH, "polymodal") with conduction velocities (CV) ranging from 0.22 to $0.70 \mathrm{~m} / \mathrm{sec}$ and mechanical (von Frey) thresholds from $8 \mathrm{mN}$ to $90.5 \mathrm{mN}$. Seven C-fibers were named high-threshold mechanusensitive (HTM) since they were not sensitive to heat and cold stimulation and the von Frey thresholds were beyond $5.6 \mathrm{mN}$ (up to $32 \mathrm{mN}$ in our sample). The C.V of these fibers ranged between 0.47 and $0.66 \mathrm{~m} / \mathrm{sec}$. One C-fiber was not sensitive to heat and cold-stimulation, had a von Frey threshold of $1 \mathrm{mN}$ and was therefore categorized as a low-threshold-mechanoreceptor (LTM). Two mechanosensitive $\mathrm{C}$ units responded to mechanical and cooling but not heat stimuli (C-MC; von Frey thresholds, 1 and $64 \mathrm{mN}$ ) and one unit responded to cooling only (C-cold).

\section{Chemosensitivity}

None of the C-MC, C-cold, or C-LTM units responded to either $\mathrm{CO}_{2}$-SIF or IS. Within the population of the seven C-HTM-fibers tested (Table 1), two units were excited by IS, by acid $\mathrm{pH}$, and responded to the combination $\left(\mathrm{CO}_{2}\right.$-IS). Six C-fibers $(\mathrm{MH}$ and HTM) developed very low frequency irregular discharge $(<12 /$ min) during acid $\mathrm{pH}$ superfusion, which could hardly be washed out and which did not increase during $\mathrm{CO}_{2}$-IS stimulation. This response pattern was previously referred to as "activated" (Steen et al., 1992). These fibers could not be identified by any other sensory properties. In this study those fibers were regarded as nonresponsive to chemical stimulation and were added to the respective group in Table 1.

In contrast, from 36 mechano-heat sensitive ("polymodal") units tested ( $5 \mathrm{~min}$ and/or $30 \mathrm{~min}$ stimulation protocols) $20 \mathrm{re}$ sponded to $\mathrm{CO}_{2}$-SIF superfusion with a duration-dependent vigorous discharge. Twelve units of the 36 were excited by IS $\left(10^{\circ} \circ\right.$ M) and all but one of these were also driven by $\mathrm{CO}_{2}$-SIF. Fifteen of the $36 \mathrm{C}-\mathrm{MH}$ fibers did not fire any spikes in response to either $\mathrm{CO}_{2}$-SIF or IS, but a significant number of these $(n=$ $6 / 15)$ were finally excited by the combination $\left(\mathrm{CO}_{2}-\mathrm{IS} ; \mathrm{pH} 6.1\right)$.
Altogether, 27 of the 36 units $(75 \%)$ were driven by the acidified IS, including all those that had previously been responsive to $\mathrm{CO}_{2}$-SIF, IS or both. We found a cross-sensitivity of polymodal (C-MH) nociceptors to acid $\mathrm{pH}$ and inflammatory mediators (IS) which was obviously restricted by the fact that the IS was used at $10^{-6} \mathrm{M}$ in a submaximal concentration. Thus, the relatively small population of IS-sensitive C-MH fibers was almost completely contained in the larger population of the $\mathrm{pH}$-sensitive ones, and this was part of the even larger group of units stimulated by acidic IS (Table 1). Out of 36 units, a total of 33 fibers underwent a protocol with $5 \mathrm{~min}$ stimulation periods; of the latter, five units received a long-term protocol in addition, and another three units were only treated with long-term stimulation for $30 \mathrm{~min}$.

\section{Comparison of excitatory potency}

To compare the excitatory potency of protons and inflammatory mediators, both were applied in almost identical concentration, and we assessed the total discharge activity within the stimulation period of $5 \mathrm{~min}$ and the subsequent washout interval of 10 min irrespective of the actual duration of the response which was usually shorter. All 33 fibers were treated with each of the three test solutions (see Materials and Methods). In most experiments (29 CMII fibers) the chemical stimulation protocol started with $5 \mathrm{~min} \mathrm{CO}_{2}$-SIF superfusion, followed by IS and then by the combination, $\mathrm{CO}_{2}$-IS, since $\mathrm{CO}_{2}$ effects were known to be rapidly washed out (Steen et al., 1992). In four cases, however, the protocol was started with IS, but the order of stimulation did not obviously influence the outcome as afterdischarge following IS had always faded during the $10 \mathrm{~min}$ interval between the chemical superfusions. Figure 1 shows specimens of three individual fibers which demonstrate the three observed patterns of synergistic interaction between low $\mathrm{pH}$ and IS. (1) fibers which responded moderately to both solutions showed more than additive excitation by the combination. (2) In other fibers, a low frequency of discharge following $\mathrm{pH}$ stimulation was enhanced by the additional presence of the inflammatory mediators; however, the IS alone was not able to excite the units. (3) 'I he mutual interaction was most impressive in cases in which the single chemicals were not able to excite the nociceptive unit, but a rather clear response was induced by the combination.

The full range of individual response magnitudes of the population of polymodal nociceptors can be seen in Figure 2. The acidified "inflammatory soup" showed the highest excitatory potency; the "gothic" appearance of the figure in general and of the median in particular illustrate the relative efficacy of the solutions in driving nociceptors: $\mathrm{CO}_{2}-\mathrm{IS}>\mathrm{CO}_{2}$-SIF $\gg$ IS. Superfusion of the receptive fields with $\mathrm{CO}_{2}$ IS was most effective in all ( $n=19$ ) but three cases, and $\mathrm{CO}_{2}-\mathrm{SIF}$ was more effective than IS in all $(n=18)$ but one case.

The individual data displayed in Figure 2 has been pooled in two different groups of CMH-subpopulations in order to set up Figure 3. One category (Fig. 3A) encompassed the fibers responsive to $\mathrm{CO}_{2}-\mathrm{IS}$, the strongest stimulus, and the other category (Fig. $3 B$ ) included the particularly chemosensitive units responding to either of the superfusions. While Table 1 showed the higher prevalence of responsiveness upon $\mathrm{CO}_{2}$-IS stimulation (including sustained-stimulation protocol), Figure 3 statistically demonstrates that the combined solution is more potent regarding the average magnitude of the excitatory effect. On average (Fig. 3A), we achieved 152 spikes with the combination $\left(\mathrm{CO}_{2}\right.$-IS) versus 45.5 spikes evoked by IS and 93 spikes by $\mathrm{CO}_{2}-$ 

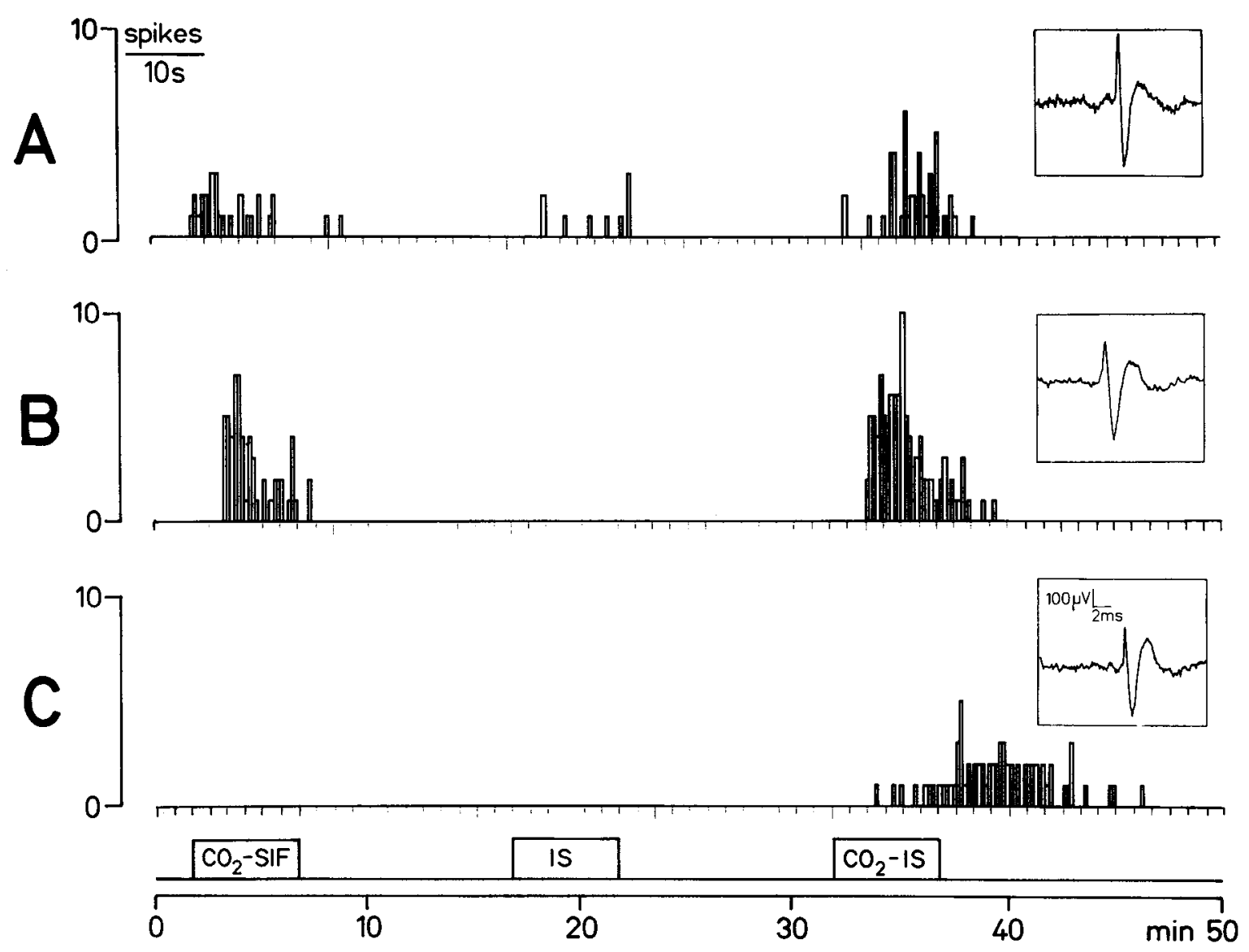

Figure 1. Specimen records (PST-histograms) from polymodal nociceptors displaying the three patterns of chemical responsiveness encountered. $A$, A unit responding to low $\mathrm{pH}\left(\mathrm{CO}_{2}-\mathrm{SIF}, \mathrm{pH} 6.1\right)$ and to inflammatory mediators but showing strong response to the combination $\left(\mathrm{CO}_{2}-\mathrm{IS}\right)$. $B$, A unit responding to low $\mathrm{pH}$, not to inflammatory mediators but with an increased discharge to the combination. $C$, A unit insensitive to low $\mathrm{pH}$ and inflammatory mediators but responding to the combination. The insets display the action potentials as recorded from thin filaments of rat saphenous nerve, in vitro.

SIF. The differences in response magnitude (number of spikes) were significant. In contrast, in the constrained tiber population (Fig. $3 B$ ) the $\mathrm{CO}_{2}$-SIF (192 spikes) and $\mathrm{CO}_{2}$-IS (255 spikes) response magnitudes were not significantly different, but the difference in response magnitude between IS (74 spikes) and $\mathrm{CO}_{2}-$ IS became even more prominent. This again, indicates a relatively low weight of IS $\left(10^{-6} \mathrm{M}\right)$ in combination with acid $\mathrm{pH}$. The acidification of IS increased the response magnitude of the particularly chemosensitive units by more than $300 \%$, on average, and decreased the individual response latency in almost all cases $[\bar{x}=49 \mathrm{sec}($ SEM 6.4) to $35 \mathrm{sec}($ SEM 7.2)].

\section{Sustained stimulation}

Five fibers which underwent the short-term protocol first and proved to provide particularly stable recordings were finally used for sustained chemical stimulations in order to demonstrate long-term effectiveness and lack of tachyphylaxis. In order to be selected, these fibers had to be mechanically excitable, had to provide stable spike amplitudes and had not to show ongoing activity. In three other fibers, long-term stimulation with acid $\mathrm{pH}$ for $30 \mathrm{~min}$ was employed without previous $5 \mathrm{~min}$ stimulations. In the long-term protocol, during the middle $10 \mathrm{~min}$ period, the receptive fields were superfused with $\mathrm{CO}_{2}$-IS (Fig. 4A,B). One fiber was treated with 20 min IS stimulation and $\mathrm{CO}_{2}$-IS during the middle $10 \mathrm{~min}$ period ( $\mathrm{Fig}$. $4 \mathrm{C}$ ). The combination $\mathrm{CO}_{2}-\mathrm{IS}$ increased the mean discharge during the ten-minutes period sig- nificantly $[n=7 ; p<0.02$ (Wilcoxon)]; there was no significant difference between the first (before $\mathrm{CO}_{2}-\mathrm{IS}$ ) and the second (after $\mathrm{CO}_{2}$-IS) $10 \mathrm{~min}$ period of $\mathrm{CO}_{2}$-SIF stimulation. Three typical patterns of responsivencss-csscntially the same as in Figure 1 -were observed in these experiments and are displayed in Figure 4.

As a specimen, Figure $4 A$ shows a $\mathrm{CMH}$-unit which had previously not responded to $5 \mathrm{~min}$ stimuli of low $\mathrm{pH}$ and of IS. Even during sustained application of $\mathrm{pH} 6.1\left(\mathrm{CO}_{2}-\mathrm{SIF}\right)$ no activity evolved. However, during superfusion of the receptive field with acidified IS $\left(\mathrm{CO}_{2}\right.$-IS $)$ a tonic low frequency discharge developed and later faded when the inflammatory mediators were again omitted from the superfusate. This unit is the same one as displayed in Figure $1 C$. Another unit, shown in Figure $4 B$ had previously not responded to inflammatory mediators (5 min) but developed a low frequent discharge during sustained application of low $\mathrm{pH}$. When inflammatory mediators were added to the acid solution ( $\mathrm{pH} 6.1$ ), the activity was greatly enhanced but subsided when the inflammatory mediators were washed out with $\mathrm{CO}_{2}$-SIF. Figure $4 \mathrm{C}$ shows the response of a unit that had previously revealed a poor sensitivity to low $\mathrm{pH}$ (5 min). It responded to the sustained superfusion with inflammatory mediators but, due to the typical tachyphylaxis, the effect was lost within $5 \mathrm{~min}$. However, acidification of the superfusate more than recovered the activity quickly, and later it subsided rapidly when the $\mathrm{pH}$ was neutralized again. It appears with the 


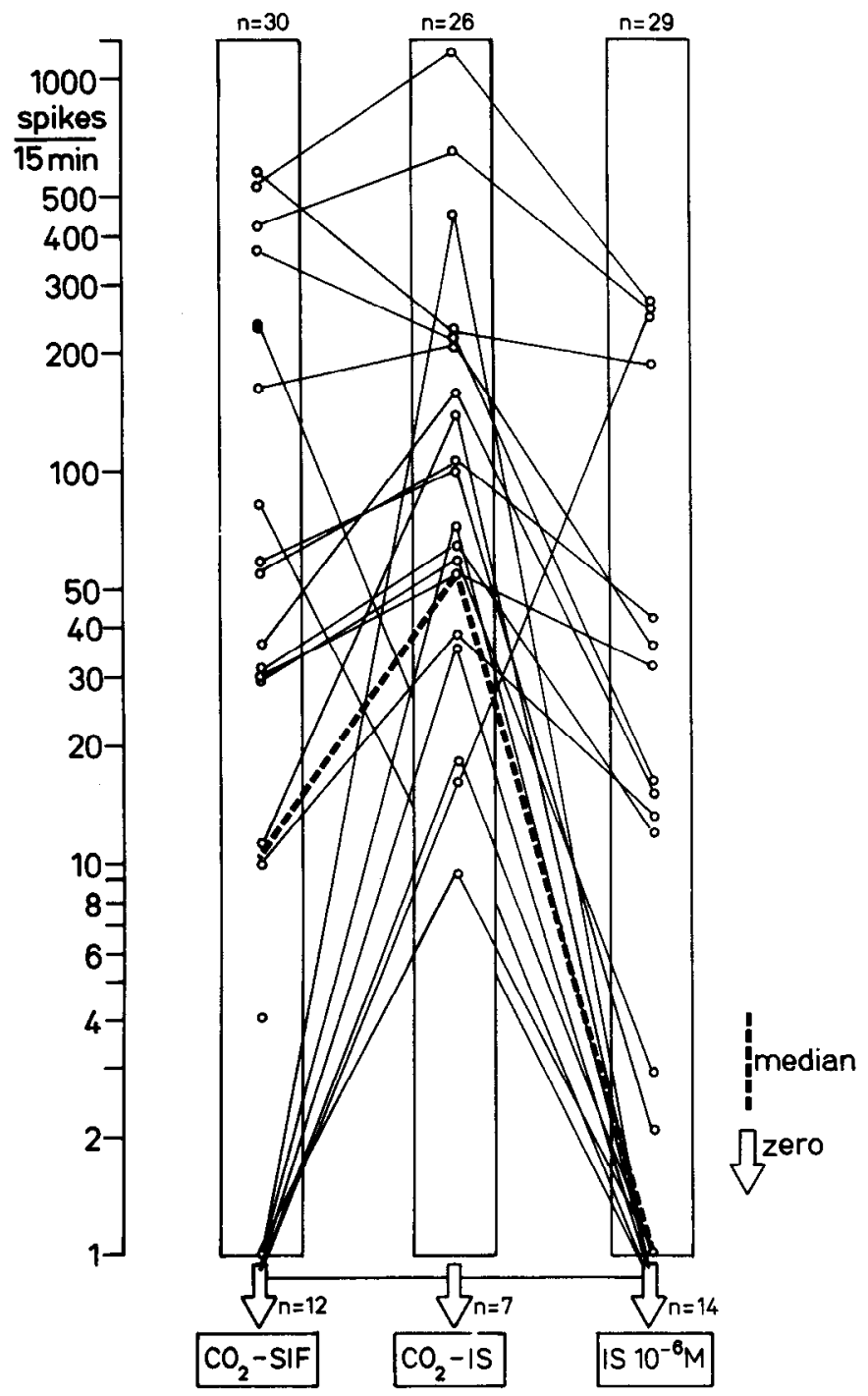

Figure 2. Individual response magnitudes of polymodal nociceptors (C-MH fibers) stimulated by superfusion of different chemical solutions for 5 min. The open arrows point to a number of units $(n)$ not responding to the particular stimulus. The connecting lines refer to individual units receiving two or, as mostly, three superfusions applied, mostly, in the order $\mathrm{CO}_{2}-\mathrm{SIF} / \mathrm{IS} / \mathrm{CO}$, IS at $10 \mathrm{~min}$ interval. The dotted line shows the median responses. Results from statistical analyses based on this individual data are given in Figure 3.

latter pattern of responsiveness that low $\mathrm{pH}$ was a necessary but not sufficient condition for excitation, becoming sufficient only through a sensitizing effect of the inflammatory mediators. In Figure $4 B$ (and $A$ ), this sensitizing effect seems to outlast the presence of inflammatory mediators for several minutes and hence to maintain the $\mathrm{pH}$-induced discharge for a few further minutes.

\section{Discussion}

It has previously been shown that pathophysiologically relevant hydrogen ion concentrations are able to excite and sensitize cutaneous nociceptors, in vitro, in a sustained manner (Steen et al., 1992). On the other hand, an ample combination of inflammatory mediators, bradykinin (BK), 5-HT, histamine (HIS), and prostaglandin $\mathrm{E}_{2}\left(\mathrm{PGE}_{2}\right)$, could also excite these nociceptors despite a certain tachyphylaxis or adaptation (Kessler et al., 1992).
Thus, it was obvious to study whether protons interact with mediators of inflammation in increasing and/or prolonging the nociceptor discharge, which turned out to be the case.

The combination of substances used as "inflammatory soup" (IS) in this study is somewhat arbitrary since possibly important inflammatory agents (c.g., cytokines and nucleotides) or chemical properties (e.g., hyperosmolarity) were not taken into account. Also, the time courses of appearance and disappearance of mediators in different stages and types of inflammations were not accounted for. Nevertheless, the model had previously, using substance $P$, proven suitable in detecting synergistic interactions between single and combined mediators and in evaluating the relative significance of one additional mediator in the inflammatory exudate (Kessler et al., 1992).

Because of the well-established sensitivity of small afferent fibers to inflammatory mediators (Kumazawa et al., 1987; Neugebauer et al., 1989; Lang et al., 1990; Kessler et al., 1992; Khan et al., 1992; Steen et al., 1992), we exclusively examined (47) $\mathrm{C}$-fiber units. According to a previous study in vitro, hydrogen ions selectively excite "polymodal" and "high-threshold mechanosensitive" C-fibers (Steen et al., 1992). The categorization into HTM and MH C-units was limited by the intensity of heat stimulation $\left(52^{\circ} \mathrm{C}\right.$, epidermal) to the extent that some fibers, now categorized into the HTM group, might have responded to higher stimulus temperatures and were therefore MH nociceptors in reality (Fleischer et al., 1983). Since both groups were treated in the same way in the experiments (and responded about equally to chemicals), the results are not affected. In the present study, we investigated the particularly chemosensitive subpopulation of C-units, 36 "polymodals," and found $20(55 \%)$ responsive to low $\mathrm{pH}$ (6.1) which was produced hy $\mathrm{CO}_{2}$ gassing of the superfusate. In terms of prevalence, that is, number of units excited, $\mathrm{BK}\left(10^{-5} \mathrm{M}\right)$ and low $\mathrm{pH}(6.1)$ are the most effective single agents, each driving a similar percentage of the polymodals (Lang et al., 1990; Steen et al., 1992). Kessler et al. (1992) investigated 72 polymodal $\mathrm{C}$-units and found $80 \%$ excited by IS in 10 -fold higher concentration $\left(10^{-5} \mathrm{M}\right)$ than used in this study which found $33 \%$ of the $\mathrm{CMH}$ units to be excited with IS $10^{-6}$ M. The $10^{-5} \mathrm{M}$ concentration of IS led to a sustained excitation of the responsive nociceptors, whereas IS in a $10^{-6} \mathrm{M}$ concentration caused an adapting discharge of the units (see Fig. $4 C$ and Reischl, Steen, and Reeh, unpublished observations). In this study, we used IS in this submaximal $\left(10^{-6} \mathrm{M}\right)$ concentration to avoid occlusion ("ceiling") of the effects which tend to be maximal at $10^{-5} \mathrm{M}$ concentration (Lang et al., 1990). Beside that, a micromolar concentration of hydrogen ions is also the result of pH 6.1; protons and inflammatory mediators would thus be compared at about equimolar concentrations. This proton concentration had previously been shown to recruit all $\mathrm{pH}$-sensitive polymodal C-fibers (Steen et al., 1992).

A major finding was that the acidification of the "inflammatory soup" ( $\mathrm{CO}_{2}$-IS) caused $75 \%$ of the nociceptive nerve fibers to discharge, and these responses were sustained for as long as the solution was superfused. Relative to the concentration, $\mathrm{CO}_{2}-$ IS was the most potent of all chemical combinations so far tested in the skin-nerve preparation. A significant number of units which were insensitive to acid $\mathrm{pH}$ as well as to IS (6 out of 15 units) were excited by the combination. The acidification of IS significantly increased the response magnitude by more than $300 \%$ on average.

Which component of the IS is the most likely agent to interact with acid $\mathrm{pH}$ ? It has been shown that $\mathrm{PGE}_{2}$ and HIS do not play 


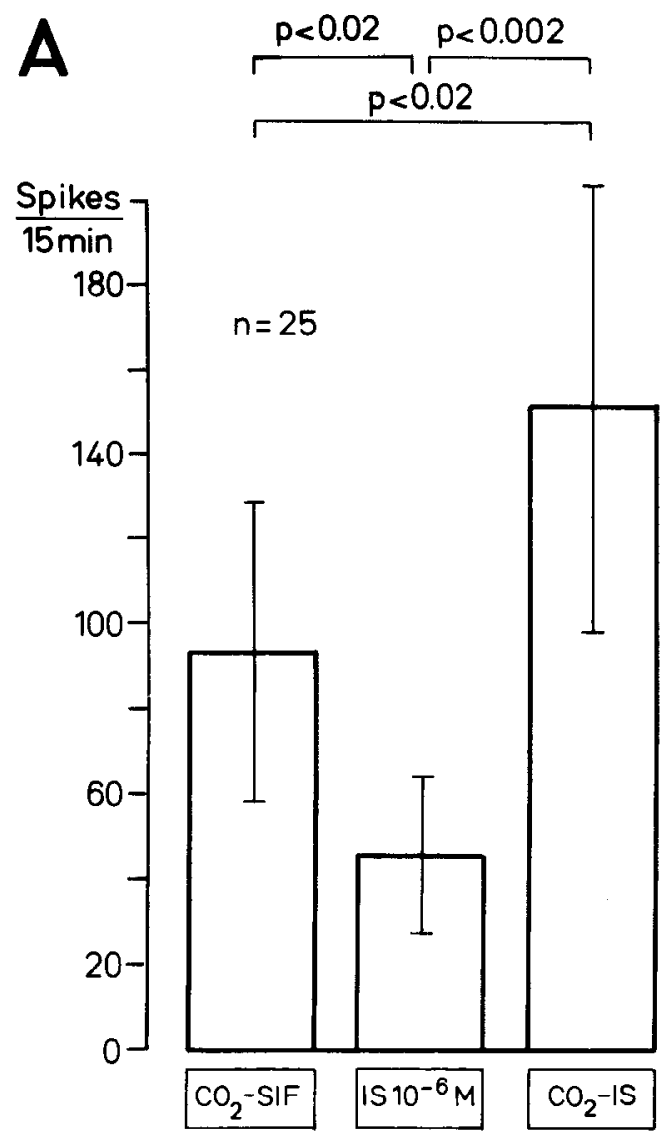

B
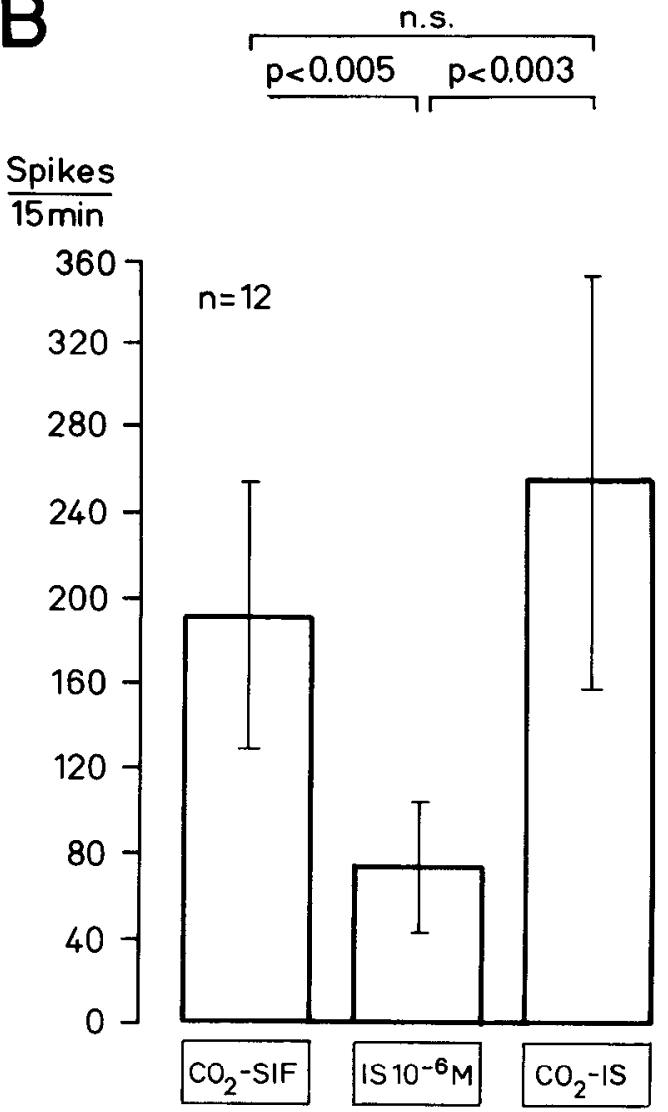

Figure 3. A shows the population of $\mathrm{C}$-MH fibers which were sensitive to $\mathrm{CO}_{2}$-IS (third column). It compares the response of these fibers with their responses to $\mathrm{CO}_{2}$ ( first column) and to IS (second column). The ordinate reproduces "spikes/15 min," which means total number of spikes counted during $15 \mathrm{~min}$ after stimulus onset including $5 \mathrm{~min}$ of stimulation and $10 \mathrm{~min}$ washout. $B$ shows the subpopulation of particularly chemosensitive C-MII fibers which responded to $\mathrm{CO}_{2}$ ( first column), IS (second column), and $\mathrm{CO}_{2}$-IS (third column), leaving out all the fibers which did not respond to any one of the stimulus solutions. $p$ values are derived from Wilcoxon test.

an important role in the IS (Lang et al., 1990). In the skin-nerve preparation, $\mathrm{PGE}_{2}$ neither excites nor sensitizes nociceptors, in contrast to the testicular preparation in vitro (Mizumura et al., 1987 ) and to the cat knee joint in vivo (Schaible and Schmidt, 1988). HIS can activate only a small population of polymodal C-fibers in our preparation. It did excite these fibers significantly more after BK pretreatment, but its effect did not add to an ongoing BK-induced discharge (Koppert et al., 1993). BK and 5-HT, each excite a proportion of nuciceptors, and 5-HT is able to sensitize the nociceptors for the action of BK (Lang et al., 1990). The excitatory effect of IS seems to depend strongly on this sensitization, since the $5-\mathrm{HT}_{3}$ antagonist metoclopramide can suppress the IS response reversibly (Handwerker et al., 1990). Thus, there are indications that BK and 5-HT are the most important compounds in the IS and the most likely candidates for an interaction with hydrogen ions.

There are a few, yet vague indications from our data that the interaction of low $\mathrm{pH}$ and inflammatory mediators is not really reciprocal:

(1) Only one fiber was found that responded to IS but not to $\mathrm{CO}_{2}$. Thus, an increase of the IS response by a possible sensitizing (not excitatory) effect of $\mathrm{CO}_{2}$ could hardly be demonstrated, whereas the reciprocal-increase of $\mathrm{CO}_{2}$ response by a sensitizing (not excitatory) effect of IS-was a regular finding.

(2) The abrupt time course of the $\mathrm{CO}_{2}$ effects, in contrast to the slowly developing and outlasting action of the inflammatory mediators in the long-term stimulation experiments, strongly suggest an excitatory role for low $\mathrm{pH}\left(\mathrm{CO}_{2}\right)$ and a sensitizing one for IS (see Fig. 4).

Indeed, BK is known to have a transient sensitizing action on nociceptors with respect to heat sensitivity (Kumazawa et al., 1991; Khan et al., 1992; Koltzenburg et al., 1992). Further evidence for the above distinction of the roles of $\mathrm{pH}$ and IS comes from a recently introduced psychophysiological model of $\mathrm{pH}$ induced pain (Steen and Reeh, 1993). Intracutaneous injection of IS at hardly perceivable concentration $\left(10^{-7} \mathrm{M}\right)$ left with a marked increase in painfulness of subsequent injections of acidic buffer (Steen et al., 1993). Thus, we tend to conclude that it is the inflammatory mediators that potentiate the excitatory effects of low $\mathrm{pH}$ rather than vice versa.

The transduction mechanism of proton induced nociceptor excitation is not yet perfectly clear. It has been suggested that intracellular acidification may be the basis for the excitatory effect of $\mathrm{CO}_{2}$ because of the nociceptor and lingual nerve responses being inhibited by acetazolamide (Steen et al., 1992; Komai and Bryant, 1993). In patch-clamp experiments on DRG cells, a sustained ionic inward current activated by protons has been demonstrated (Bevan and Yeats, 1991). The same authors suggested that common mechanisms of protons and of capsaicin induce excitation of sensory neurons; however, a complete cross-sensitivity to capsaicin and protons could not be confinmed in saphenous nerve endings (Steen et al., 1992). Petersen and 
Figure 4. Specimens of prolonged records (PST-histograms) from polymodal nociceptors under sustained chemical stimulation. The insets display the action potentials of the particular saphenous nerve fibers. See text for description of the response patterns.
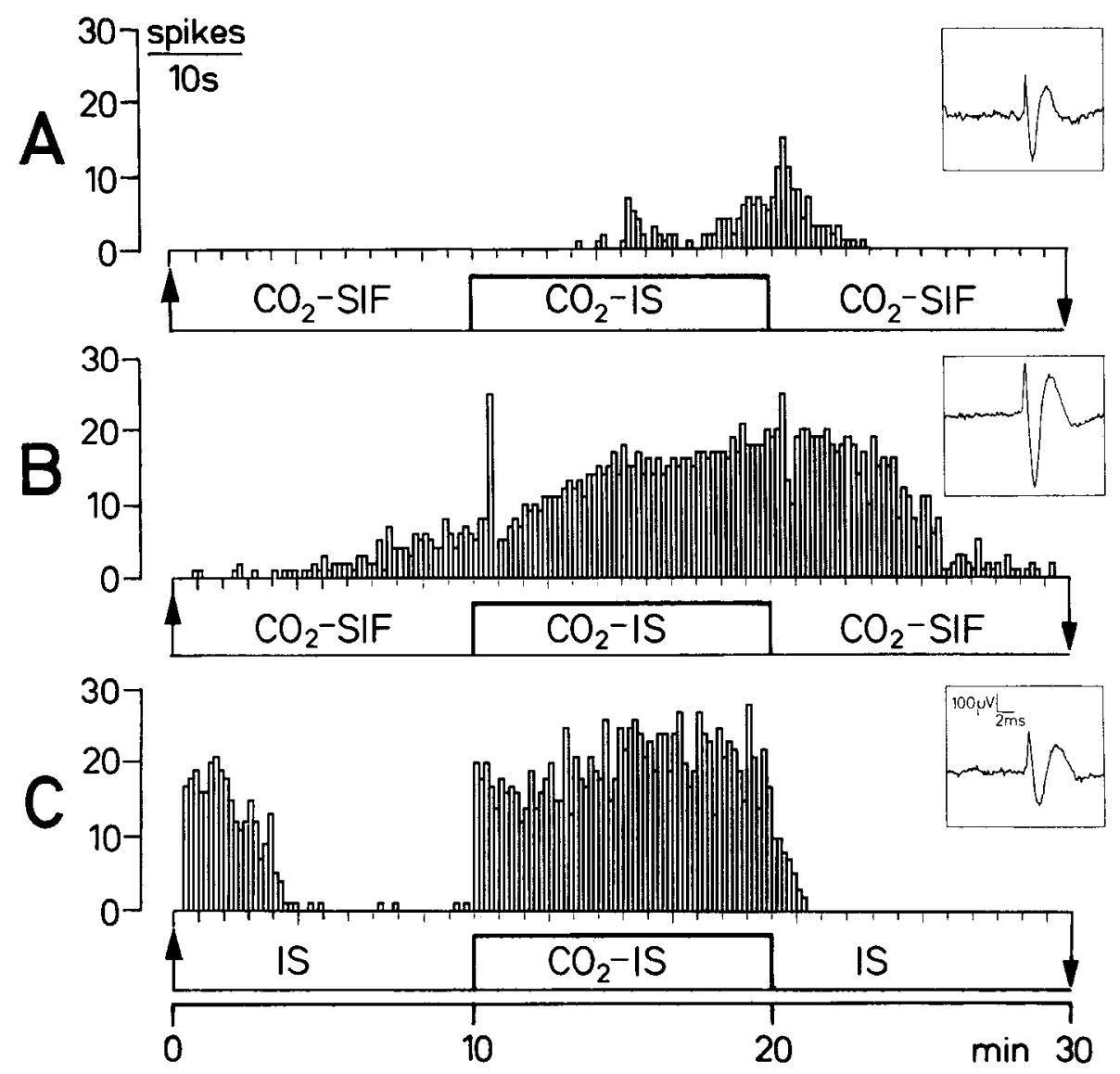

LaMotte (1993) showed an interaction in DRG cells in such a way that acidification of the extracellular medium increased the capsaicin-evoked inward current. BK also evokes an unspecific cationic inward current in these cells, which may relate to its excitatory action on nociceptive afferents (Burgess et al., 1989). On the other hand, BK also acts through $\mathrm{G}$-protein dependent activation of protein kinase $\mathrm{C}$ which may convey its sensitizing properties (Dray et al., 1988). This may provide a future working hypothesis to explain the inflammatory potentiation of the $\mathrm{pH}$ induced nociceptor discharge.

The recognition of the excitatory and the sensitizing actions of inflammatory mediators onto nociceptors did not really help to explain ongoing "spontaneous" and recurrent pain from inflamed tissues, since tachyphylaxis turned out to restrict the effects during prolonged or repeated exposure (Kanaka et al., 1985, Kumazawa et al., 1987; Handwerker et al., 1990; Lang et al., 1990; Kessler et al., 1992). Our finding of the sustained nociceptor discharge induced by the local acidosis typical to inflamed tissue filled a logical gap (Steen et al., 1992). However, to cause pain, nociceptor activity must exceed a certain, yet undefined quantity. The prominent synergism between inflammatory mediators and tissue acidosis, concluded from our results, may provide this critical quantity by increasing temporal as well as spatial summation of nociceptive input.

\section{References}

Bevan S, Yeats J (1991) Protons activate a cation conductance in a sub-population of rat dorsal root ganglion neurones. J Physiol (Lond) 433:145-161.

Bretag AH (1969) Synthetic interstitial fluid for isolated mammalian tissue. Life Sci 8:319-329.
Burgess GM, Mullaney 1, Mc Neill M, Dunn PM, Rang HP (1989) Second messenger involved in the mechanism of action of bradykinin in sensory neurons in culture. J Neurosci 9:3314-3325.

Dray A, Bettaney J, Forster P, Perkins MN (1988) Bradykinin-induced stimulation of afferent fibers is mediated through protein kinase $C$. Neurosci Lett 91:301-307.

Fjällbrand N, Iggo A (1961) The effect of histamine, 5-hydroxytryptamine and acetylcholine on cutaneous afferent fibers. J Physiol (Lond) 156:578-590.

Fleischer E, Handwerker HO, Joukhadar S (1983) Unmyelinated nociceptive units in two skin areas of the rat. Brain Res 267:81-92.

Fock S, Mense S (1976) Excitatory effects of 5-hydroxytryptamine, histamine and potassium ions on muscular group IV afferent units: a comparison with bradykinin. Brain Res 105:459-469.

Häbler C (1929) Über den K- und Ca-Gehalt von Eiter und Exsudaten und seine Beziehungen zum Entzündungsschmerz. Klin Wochenschr $8: 1569-1572$.

Handwerker HO, Reeh PW (1991) Pain and inflammation. In: Proceedings of the VIth World Congress on Pain (Bond MR, Charlton JE, Wolf CJ, eds), pp 59-70. Amsterdam: Elsevier

Hanlwerker HO, Reeh PW, Steen KH (1990) Effects of 5-HT on nociceptors. In: Serotonin and pain (Besson JM, ed), pp 1-15. Amsterdam: Elsevier.

Handwerker HO, Forster C, Kirchhoff C (1991) Discharge patterns of human $\mathrm{C}$-fibers induced by itching and burning stimuli. J Neurophysiol 66:307-315.

Iggo A (1958) The electrophysiological identification of single nerve fibres with particular reference to the slowest-conducting vagal afferent fibres in the cat. J Physiol (Lond) 142:110-112.

Jacobus WE, Taylor GJ, Hollis DP, Nunnally RL (1977) Phosphorus nuclear magnetic resonance of perfused working rat hearts. Nature 265:756-758.

Kanaka R, Schaible H-G, Schmidt RF (1985) Activation of fine articular afferent units by bradykinin. Brain Res 327:81-90.

Keele CA, Armstrong D (1964) Substances producing pain and itch. London: Arnold. 
Kessler W, Kirchhoff C, Reeh PW, Handwerker HO (1992) Excitation of cutaneous afferent nerve endings in vitro by a combination of inflammatory mediators and conditioning effect of substance P. Exp Brain Res 91:467-476.

Khan AA, Raja SN, Manning DC, Campbell JN, Meyer RA (1992) The effects of bradykinin and sequence-related analogs on the response properties of cutaneous nociceptors in monkeys. Somlatosens Mot Res 9:97-106.

Koltzenburg M, Kress M, Reeh PW (1992) The nociceptor sensitization by bradykinin does not depend on sympathetic neurones. Neuroscience 46:465-473.

Komai M, Bryant BP (1993) Acetazolamide specifically inhibits lingual trigeminal nerve responses to carbon dioxide. Brain Res 612: $122-129$.

Koppert W, Reeh PW, Handwerker HO (1993) Conditioning of histamine by bradykinin alters responses of rat nociceptor and human itch sensation. Neurosci Lett 152:117-120.

Kumazawa T, Mizumura K, Sato J (1987) Response properties of polymodal receptors studied using in vitro testis superior spermatic nerve preparations of dogs. J Neurophysiol 57:702-711.

Kumazawa T, Mizumura K, Minagawa M, Tsujii Y (1991) Sensitizing effects of bradykinin on the heat responses of the visceral nociceptor. J Neurophysiol 66:1819-1824.

Lang E, Novak A, Reeh PW, Handwerker HO (1990) Chemosensitivity of fine afferents from rat skin in vitro. J Neurophysiol 63:887-901.

Lindahl O (1974) Pain-a general chemical explanation. Adv Neurol $4: 45-47$.

Lynn B, Carpenter SE (1982) Primary afferent units from the hairy skin of the rat hind limb. Brain Res 238:29-43.

McCarty DL Jr, Phelps P, Pyenson J (1966) Crystal-induced inflammation in canine joints. J Exp Med 124:99-114.

Mizumura K, Sato J, Kumazawa T (1987) Effects of prostaglandins and other putative chemical intermediaries on the activity of canine testicular polymodal receptors studied in vitro. Pfluegers Arch 408: $565-572$

Neugebauer V, Schaible HG, Schmidt RF (1989) Sensitization of ar- ticular afferents to mechanical stimuli hy hradykinin. Pfluegers Arch 330-335.

Peer LA (1955) Transplantation of tissues. Baltimore: Williams and Wilkins.

Petersen M, LaMotte RH (1993) Effects of protons on the inward current evoked by capsaicin in isolated dorsal root ganglion cells. Pain $54: 37-42$.

Reeh PW (1986) Sensory receptors in mammalian skin in an in vitro preparation. Neurosci Lett 66:141-146.

Reeh PW, Steen KH, Hanisch AE (1991) A dominant role of acid pH in inflammatory excitation of nociceptors in rat skin. Soc Neurosci Abstr 17:537.

Revici E, Stoopen E, Frenk E, Ravich RA (1949) The painful focus. II. The relation of pain to local physico-chemical changes. Bull Inst Appl Biol 1:21.

Schaible H-G, Schmidt RF (1988) Excitation and sensitization of fine articular afferents from cat's knee joint by prostaglandin $E_{2}$. J Physiol (Lond) 403:91-104.

Steen AE, Reeh PW, Kreysel HW, Steen KH (1993) Experimental tissue acidosis potentiates pain induced by inflammatory mediators. VIIth World Congress on Pain (Paris), R 39.

Steen KH, Reeh PW (1993) Sustained graded pain and hyperalgesia from experimental tissue acidosis in human subjects. Neurosci Lett 154:113-116.

Steen KH, Hanisch AE, Reeh PW (1991) A dominant role of acid pH in inflammatory excitation of nociceptors in rat skin. Pfluegers Arch 418:R42.

Steen KH, Anton F, Reeh PW, Handwerker HO (1992) Protons selectively induce lasting excitation and sensitization to mechanical stimulation of nociceptors in rat skin, in vitro. J Neurosci 12:86-95.

von Frey M (1896) Untersuchungen über die Sinnesfunktionen der menschlichen Haut. Erste Abhandlung: Druckempfindung und Schmerz. Abh Mathem-Phys Clas Kgl Sächs Ges Wiss 23:208-217, 239.

von Gaza W, Brandi B (1926) Beziehung zwischen Wasserstoffionenkonzentration und Schmerzempfindung. Klin Wochenschr 5:11231127. 